Issues in

MENTAL

HEALTH

NURSING
Issues in Mental Health Nursing

ISSN: (Print) (Online) Journal homepage: https://www.tandfonline.com/loi/imhn20

\title{
\#Stressed: Covid-19, Chronic Illness and Technostress
}

Hema Malini, Devia Putri Lenggogeni, Andi Windah, Fauziah Qifti,
Deependra K. Thapa, Sancia West \& Michelle Cleary

To cite this article: Hema Malini, Devia Putri Lenggogeni, Andi Windah, Fauziah Qifti, Deependra K. Thapa, Sancia West \& Michelle Cleary (2021): \#Stressed: Covid-19, Chronic Illness and Technostress, Issues in Mental Health Nursing, DOI: 10.1080/01612840.2021.1958035

To link to this article: https://doi.org/10.1080/01612840.2021.1958035

册 Published online: 31 Aug 2021.

Submit your article to this journal $\llbracket$

Q View related articles $\sqsubset$

View Crossmark data 


\title{
\#Stressed: Covid-19, Chronic IIIness and Technostress
}

\author{
Hema Malini, PhD, RNa (D), Devia Putri Lenggogeni, RN, CNS ${ }^{a}$ D, Andi Windah, S.I.Kom, MComn\&Media ${ }^{b}$ \\ (D), Fauziah Qifti, RN, MNc (D), Deependra K. Thapa, MPH, MSc, PhD d,e (D), Sancia West, RN, PhDe (D) and \\ Michelle Cleary, RN, $\mathrm{PhD}^{\mathrm{e}}$
}

aFaculty of Nursing, Universitas Andalas, Padang, Indonesia; 'baculty of Social and Political Science, Universitas Lampung, Bandar Lampung,

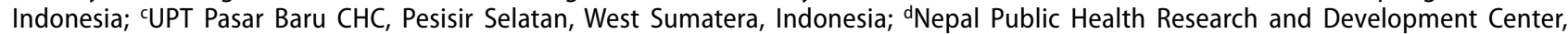
Kathmandu, Nepal; ${ }^{e}$ School of Nursing, Midwifery \& Social Sciences, Central Queensland University, Sydney, Australia

\section{Edited by}

\section{Michelle Cleary, PhD, RN}

School of Nursing, Midwifery \& Social Sciences, Central Queensland University, Sydney, NSW, Australia

\section{Introduction}

The use of online resources, particularly search engines and social media, for health-related information is on a steady upward trajectory. With its accessibility and ease of use, the Internet has founded a new era of information gathering and society has naturally gravitated towards the use of internet-based resources to find out more about all aspects of our own health (West et al., 2020). This has had rather unsurprising results for the way in which consumers engage with their health and with healthcare professionals, with many consumers armed and ready with some level of online-sourced health information prior to engaging with their local GP or specialist. The COVID-19 pandemic, with its sudden onset and widespread ramifications, gave many people yet another reason to pick up their smartphones and utilise online health resources to understand something that came to affect almost every person in one way or another, and became a pervasive part of our everyday lives. Indeed, with COVID-19 necessitating a reduced amount of travel and face to face contact with healthcare professionals, online platforms have become an essential way of accessing this information.

However, research assessing knowledge and perceptions of COVID-19 among the general public indicates that participants have been prone to believe some misconceptions and falsehoods circulated particularly on social media (Geldsetzer, 2020). Ready access to a large amount of information about COVID-19 on social media coupled with its problematic use, including misinformation, has contributed to high levels of stress and cognitive symptoms called 'technostress'. Brod (1984) originally defined 'technostress' as the inability to adapt to computer technology in a healthy way. Tarafdar et al. (2011) describe five technostress conditions: namely techno-overload, where users cannot determine whether the information is useful or not; techno-invasion, where technology users never feel free from technology; techno-complexity, where users experience feelings of incompetency and powerlessness from an inability to learn or deal with technology; techno-insecurity, marked by feelings of anxiety about using technology; and techno-uncertainty, where constant changes in technology cause stress to the user.

While patients with health conditions require timely access to healthcare information, they often use information technology, including social media, to access such information. Subsequently, patients with chronic illnesses, who have a higher-than-average need for health information, may be exposed to information that is incomplete, conflicting, misleading, or inaccurate. This may place patients at increased risk of technostress. Couple this with an increased urgency in accessing online health information to stay abreast of COVID-19 information and there is an increased risk for technostress amongst an already vulnerable group, and scope for this technostress to tip over into the realm of physical and mental health impact. What needs to be understood is the extent to which technostress, exacerbated by COVID-19 information-seeking and coupled with chronic illness, manifests as a mental health challenge for those experiencing this. If the need for information draws those with a chronic illness further into the use of media platforms that can, in turn, trigger technostress, how can we identify and manage the potential mental health impacts of this illness-stress combination? Additionally, is this group more likely to experience technostress and ensuing physical and mental health impacts as a consequence of their chronic illnesses during the COVID-19 pandemic? With these questions in mind the authors undertook research into this area of crossover between chronic illness and technostress.

\section{Method}

The study used an online self-report survey among participants with a chronic health condition. The study was approved by the Ethics Committee, Faculty of Medicine, Andalas University (Approval number 333/KEP/FK/2020). A non-probability sampling strategy was used in which an online questionnaire using Google Forms was circulated via 
the messaging app 'WhatsApp' to adults with a chronic condition. These adults were identified by nurses in charge of the chronic disease programs in community health centres in Padang city, Indonesia (July to September, 2020). After providing informed consent, participants completed the online self-reported measures of technostress and its implications for their health.

The Technostress Questionnaire, developed by Tarafdar et al. (2011, 2007), was modified and contextualised to the use of social media to access COVID-19 related information. Twenty-three questions measured the five components of technostress. To assess the impact of technology on participants' health, further questions were developed by the research team that measured biological (three questions), physiological (five questions) and psychological (nine questions) aspects. These questions were also informed by Boonjing and Chanvarasuth (2007), Gaudioso, Turel, and Galimberti (2007) and Tarafdar and colleagues (2007) research. A 5-point Likert-type scale measured responses from strongly agree (1) to strongly disagree (5). The possible range for the total technostress score was 23 to 115 , and for patients' health impact measurement was 17 to 85 . Higher scores were indicative of a higher level of technostress and more adverse impact on the participants' health. The survey showed good internal consistency, with an overall Cronbach alpha coefficient of 0.92 for the technostress scale and 0.93 for the patients' health impact measurement.

\section{Results}

A total of 107 participants completed the survey, consisting largely of women (62.2\%) and patients with diabetes (63.6\%). Hypertension and other lung and kidney related conditions were also represented in the sample (see Table 1).

What the results demonstrated was that technostress and flow-on health impacts were high for this group. Most

Table 1. Socio-demographic characteristics of the study sample.

\begin{tabular}{|c|c|c|}
\hline Characteristics & $\mathrm{n}$ & $\%$ \\
\hline $\begin{array}{l}\text { Age, mean (SD) years } \\
\text { Occupation }\end{array}$ & $51(5.9)$ & \\
\hline Household duties & 39 & 36.4 \\
\hline Private company & 31 & 29.0 \\
\hline Govt. employee & 23 & 21.5 \\
\hline Retired & 14 & 13.1 \\
\hline \multicolumn{3}{|l|}{ Sex } \\
\hline Women & 67 & 62.6 \\
\hline Men & 40 & 37.4 \\
\hline \multicolumn{3}{|l|}{ Health condition } \\
\hline Diabetes & 68 & 63.6 \\
\hline Hypertension & 14 & 13.1 \\
\hline Diabetes and hypertension & 18 & 16.8 \\
\hline Other (lung/kidney) & 7 & 6.5 \\
\hline \multicolumn{3}{|l|}{ Length of diagnosis } \\
\hline$<1$ year & 9 & 8.4 \\
\hline $1-5$ years & 49 & 45.8 \\
\hline$>5$ years & 49 & 45.8 \\
\hline \multicolumn{3}{|l|}{ Marital status } \\
\hline Married & 97 & 90.7 \\
\hline Single & 10 & 9.3 \\
\hline \multicolumn{3}{|l|}{ Economic status } \\
\hline Low income & 81 & 75.7 \\
\hline Middle income & 25 & 23.4 \\
\hline High income & 1 & 0.9 \\
\hline
\end{tabular}

participants (80.4\%) had access to the Internet through their mobile phones. COVID-19 related information was being accessed from social media platforms including Facebook (48.6\%), YouTube $(29.9 \%)$, Instagram (16.8\%), and others (4.7\%). The frequency of accessing COVID-19 related information showed high levels of access, with $25 \%$ of respondents indicating that they were accessing information via social media platforms more than 10 times per day. Time spent at each point of access was also more than 30 minutes for over $25 \%$ of respondents.

So, what were the consequences of frequent and extended periods of social media access to COVID-19 information? Table 2 shows the mean technostress of participants with chronic diseases was $73.7(\mathrm{SD}=16.0)$, being on the higher end of the possible range between 23 and 115. Meanwhile, the mean impact on patient's health was 49.5 in the possible range between 27 and 70 . This indicates that participants experienced medium to high levels of technostress from attempting to access information related to COVID-19 which then impacted their health conditions unrelated to COVID-19. Participants were overwhelmed with the information derived from social media, and experienced insecurity about COVID-19 related information in relation to their own conditions. In an illustration of techno-invasion, participants reported wanting current news about COVID-19 even when this information was not directly related to their condition, taking extra effort to access and understand COVID-19 related information. Consequently, more time was spent using technology to access current COVID-19 information.

The results demonstrated high levels of technostress with participants experiencing medium to high impact on their overall physical and mental health. Participants reported physical impacts such as stiffness of the neck, shortness of breath, sore throats, and cramps. This may be a result of COVID-19 information manifesting in a stress response, possibly due to persistent stressors interrupting the body's hormonal regulation. However, respondents also stated the information on COVID-19 that they get through social media had impacts such as loss of appetite, difficulty sleeping and loss of libido. Direct mental health impacts were also reported and included anxiety, unhappiness, fear, worry, and withdrawal from their external environment.

The relationship between technostress and the impact on patients' health was examined using Spearman's correlation coefficient (Table 3). A strong positive correlation was observed between the total technostress score and the impact on health condition $(r=0.76, p<0.001)$, suggesting a high level of technostress associated with higher impacts on patients' health. Table 3 also shows that all the subscales of technostress correlated positively with the subscales of impact on patients' health with $p<0.001$.

\section{Discussion}

What do these results mean in reality and what changes do they suggest for the way in which healthcare professionals, particularly mental health professionals, approach the issue of technostress amongst those with chronic illness? The results 
Table 2. Descriptive statistics for technostress and impact on patients' health

\begin{tabular}{|c|c|c|c|c|}
\hline Variable & Mean (SD) & Median & Min-Max & $95 \% \mathrm{Cl}$ \\
\hline Technostress & $73.74(15.95)$ & 74 & 38-115 & $70.88-76.80$ \\
\hline Overload & $14.81(4.89)$ & 15 & $5-25$ & $13.88-15.75$ \\
\hline Invasion & $13.61(3.77)$ & 14 & $6-20$ & $12.88-14.33$ \\
\hline Complexity & $16.00(3.18)$ & 16 & $8-25$ & $15.39-16.61$ \\
\hline Insecurity & $18.02(3.59)$ & 18 & $10-25$ & $17.33-18.71$ \\
\hline Uncertainty & $11.30(4.51)$ & 12 & $4-20$ & $10.44-12.16$ \\
\hline Impact on patients' health & $49.48(9.82)$ & 48 & 27-70 & $45.72-49.48$ \\
\hline Biological & $11.38(2.15)$ & 12 & $6-15$ & $10.97-11.79$ \\
\hline Physiological & $15.52(3.34)$ & 16 & $7-20$ & $14.88-16.16$ \\
\hline Psychological & $20.69(5.67)$ & 20 & $10-35$ & $19.60-21.28$ \\
\hline
\end{tabular}

Table 3. Paired-wise correlation among technostress and impact on patients' health.

\begin{tabular}{|c|c|c|c|c|c|c|c|c|c|c|c|}
\hline & Variables & 1 & 2 & 3 & 4 & 5 & 6 & 7 & 8 & 9 & 10 \\
\hline 1 & Technostress (Total) & - & & & & & & & & & \\
\hline 2 & Techno-Overload & 0.82 & - & & & & & & & & \\
\hline 3 & Techno-Invasion & 0.88 & 0.79 & - & & & & & & & \\
\hline 4 & Techno-Complexity & 0.78 & 0.47 & 0.60 & - & & & & & & \\
\hline 5 & Techno-Insecurity & 0.78 & 0.58 & 0.65 & 0.64 & - & & & & & \\
\hline 6 & Techno-Uncertainty & 0.68 & 0.37 & 0.42 & 0.61 & 0.36 & - & & & & \\
\hline 7 & Impact on health condition (Total) & 0.76 & 0.55 & 0.62 & 0.63 & 0.64 & 0.63 & - & & & \\
\hline 8 & Biological & 0.69 & 0.54 & 0.59 & 0.54 & 0.67 & 0.46 & 0.90 & - & & \\
\hline 9 & Physiological & 0.65 & 0.49 & 0.53 & 0.55 & 0.65 & 0.42 & 0.89 & 0.76 & - & \\
\hline 10 & Psychological & 0.67 & 0.47 & 0.56 & 0.52 & 0.43 & 0.67 & 0.78 & 0.60 & 0.51 & - \\
\hline
\end{tabular}

Note: All correlations were significant at $p<0.001$ (2-tailed).

seem somewhat unsurprising based on what is already understood about social media use and technostress in workplaces and amongst students, for example. Research by Boonjing and Chanvarasuth (2017) showed similar findings that excessive use of mobile or smartphones was associated with technostress in the workplace. The results further indicated that employees who often use smartphones may similarly experience physical and psychological health problems. The results are further echoed by Hsiao et al. (2017) whose survey into university students' compulsive use of social media found this had significant positive correlations with technostress. Furthermore, a study among Chinese university students who used social media daily revealed that techno-overload resulted in physical conditions such as exhaustion (Shi et al., 2020).

What these results reveal is that a perfect storm has been created under COVID-19. Participants with chronic conditions were found to be active users of social media and readily used social media to access COVID-19 information. This would be a natural extension to their existing health conditions and efforts to access information in relation to these. However, this information-accessing behaviour fuelled technostress which in turn adversely impacted their physical, psychological, and mental health. Thus, those with already compromised health were further compromised as a result of their efforts to seek information on COVID-19. This included mental health impacts such as anxiety, worry and unhappiness. Research has already highlighted the strong link between chronic illness and increased levels of mental health disorders (Adams et al., 2019; Vancampfort et al., 2017). Our study has highlighted that the increased level of technostress among patients with chronic conditions due to increased access and use of social media may further deteriorate their mental and physical health.

There are easy and tangible things that healthcare professionals can do to respond effectively to this 'perfect storm' of COVID-19, technostress, and chronic illness. Online health information, including social media has many great uses and can be a constructive platform for education and information for health consumers (Lin et al., 2020; Thapa et al., 2021). The aim is to ensure that the constructive ways of using social media are promoted and the counterproductive ways are counteracted. Things to consider may start with a quick mental health check-in for patients with a chronic illness when healthcare professionals are interacting with them to note any changes in the patient. Healthcare professionals can give patients details of a reliable site, such as the Department of Health, where they might consider accessing the information about COVID-19 to avoid misleading or incorrect information. Health professionals can promote the use of sites that provide reliable educational material about the patient's illness to support them in their search for information that may be more directly relevant to their own circumstances (Thapa et al., 2021; West et al., 2020). Likewise, organisations that provide such information on chronic disease and conditions can tap into the increased health information-seeking behaviours to grow their visibility and capture their target population. Most importantly, however, each healthcare professional who has cause to believe that a patient with an illness is experiencing technostress or subsequent mental health impacts needs to encourage that person to speak to someone appropriate to the circumstances and provide information on how to contact the right person.

This study is not without limitations. First, this study found a significant positive correlation of technostress and impact on physical and mental health among patients with chronic conditions as a result of social media use to access online health information. However it is unclear how, and what information was obtained by patients and how their perception impacts their knowledge about management of the chronic condition. Second, convenience sampling and an online survey 
were used, which might limit the generalisability of the findings. Third, the lack of previous studies on technostress among patients with chronic conditions during the COVID-19 pandemic limited the comparison of our findings to other studies.

\section{Conclusion}

With the pressure of the COVID-19 outbreak and increased social media use in accessing COVID-19 related information, general populations especially people living with chronic conditions may experience technostress. Technostress may adversely affect physical and mental health status. There may be a need for healthcare providers to assess and encourage some individuals to curtail their use of social media to access pandemic related information, and to suggest sources of information which are reliable, valid, and accurate.

\section{Conflicts of interest}

No conflict of interest has been declared by the authors.

\section{Funding}

Partially funded by a grant from Faculty of Nursing Universitas Andalas, Number 03/SPK/PNBP/FKep/Unand-2020.

\section{ORCID}

Hema Malini (D) http://orcid.org/0000-0002-3224-5657

Devia Putri Lenggogeni (ID http://orcid.org/0000-0002-2436-5149

Andi Windah (D) http://orcid.org/0000-0003-3094-7759

Fauziah Qifti iD http://orcid.org/0000-0001-8109-4296

Deependra K. Thapa (D) http://orcid.org/0000-0002-5689-0837

Sancia West (D) http://orcid.org/0000-0001-7738-9390

Michelle Cleary (D) http://orcid.org/0000-0002-1453-4850

\section{References}

Adams, J. S., Chien, A. T., \& Wisk, L. E. (2019). Mental illness among youth with chronic physical conditions. Pediatrics, 144(1), e20181819. https://doi.org/10.1542/peds.2018-1819
Boonjing, V., \& Chanvarasuth, P. (2017). Risk of overusing mobile phones: Technostress effect. Procedia Computer Science, 111, 196202. https://doi.org/10.1016/j.procs.2017.06.053

Brod, C. (1984). Technostress: The human cost of the computer revolution. Basic Books.

Gaudioso, F. Turel, O., \& Galimberti, C. (2017). The mediating roles of strain facets and coping strategies in translating techno-stressors into adverse job outcomes. Computers in Human Behavior, 69, 189-196. https://doi.org/10.1016/j.chb.2016.12.041

Geldsetzer, P. (2020). Knowledge and perceptions of COVID-19 among the general public in the United States and the United Kingdom: A cross-sectional online survey. Annals of Internal Medicine, 173(2), 157-160. https://doi.org/10.7326/M20-0912

Hsiao, K.-L., Shu, Y., \& Huang, T.-C. (2017). Exploring the effect of compulsive social app usage on technostress and academic performance: Perspectives from personality traits. Telematics and Informatics, 34(2), 679-690. https://doi.org/10.1016/j.tele. 2016.11.001

Lin, C. Y., Broström, A., Griffiths, M. D., \& Pakpour, A. H. (2020). Investigating mediated effects of fear of COVID-19 and COVID-19 misunderstanding in the association between problematic social media use, psychological distress, and insomnia. Internet Interventions, 21, 100345. https://doi.org/10.1016/j.invent.2020.100345

Shi, C., Yu, L., Wang, N., Cheng, B., \& Cao, X. (2020). Effects of social media overload on academic performance: A stressor-strainoutcome perspective. Asian Journal of Communication, 30(2), 179_ 197. https://doi.org/10.1080/01292986.2020.1748073

Tarafdar, M., Tu, Q., Ragu-Nathan, B. S., \& Ragu-Nathan, T. S. (2007). The impact of technostress on role stress and productivity. Journal of Management Information Systems, 24(1), 301-328. https://doi. org/10.2753/MIS0742-1222240109

Tarafdar, M., Tu, Q., Ragu-Nathan, T. S., \& Ragu-Nathan, B. S. (2011). Crossing to the dark side: Examining creators, outcomes, and inhibitors of technostress. Communications of the ACM, 54(9), 113120. https://doi.org/10.1145/1995376.1995403

Thapa, D. K., Visentin, D. C., Kornhaber, R., West, S., \& Cleary, M. (2021). The influence of online health information on health decisions: A systematic review. Patient Education and Counseling, 104(4), 770-784. https://doi.org/10.1016/j.pec.2020.11.016

Vancampfort, D., Koyanagi, A., Hallgren, M., Probst, M., \& Stubbs, B. (2017). The relationship between chronic physical conditions, multimorbidity and anxiety in the general population: A global perspective across 42 countries. General Hospital Psychiatry, 45, 1-6. https://doi.org/10.1016/j.genhosppsych.2016.11.002

West, S., Kornhaber, R., Visentin, D. C., Thapa, D. K., \& Cleary, M. (2020). The role of the health professional supporting consumers who use 'Dr Google'. Journal of Advanced Nursing, 76(9), 2217-2219. https://doi.org/10.1111/jan.14419 